OCCASIONAL REVIEW

\title{
Lung cancer in HIV infected patients: facts, questions and challenges
}

\author{
J Cadranel, D Garfield, A Lavolé, M Wislez, B Milleron, C Mayaud
}

Thorax 2006;61:1000-1008. doi: 10.1136/thx.2005.052373

AIDS related mortality has fallen sharply in industrialised countries since 1996 following the introduction of highly active antiretroviral therapy. This has been accompanied by an increase in the proportion of deaths attributable to non-AIDS defining solid tumours, especially lung cancer. The risk of developing lung cancer seems to be higher in HIV infected subjects than in the general population of the same age, partly because the former tend more frequently to be smokers and, especially, intravenous drug users. The carcinogenic role of the antiretroviral nucleoside drugs and their interaction with smoking needs to be examined. Interestingly, there is no clear relationship between the degree of immunosuppression and the risk of lung cancer, so the reason for the increased risk is unknown. The mean age of HIV infected patients at the time of lung cancer diagnosis is $\mathbf{4 5}$ years and most are symptomatic. Lung cancer is diagnosed when locally advanced or metastatic (stage III-IV) in 75-90\% of cases, similar to patients with unknown HIV status. Adenocarcinoma is the most frequent histological type. The prognosis is worse in HIV infected patients than in the general lung cancer population. Efficacy and toxicity data for chemotherapy and radiation therapy are few and imprecise. Surgery remains the treatment of choice for localised disease in patients with adequate pulmonary function and general good health, regardless of immune status. Prospective clinical trials are needed to define the optimal detection and treatment strategies for lung cancer in HIV infected patients.

See end of article for authors' affiliations

Correspondence to:

Professor J Cadranel,

Service de Pneumologie et Réanimation Respiratoire, Hôpital Tenon, 4 rue de la Chine 75970, Paris cedex 20, France; jacques. cadranel@tnn.aphp.fr

Received

12 September 2005

Accepted 21 March 2006 ung cancers were reported in HIV infected $(\mathrm{HIV}+)$ patients early in the AIDS epidemic. ${ }^{1-3}$ - A relatively high frequency of adenocarcinoma and advanced disease at diagnosis was noted, as was the poor prognosis. Surprisingly, however, no correlation was noted between lung cancer and the degree of immune deficiency at diagnosis. $^{4-6}$

Subsequently, some epidemiological ${ }^{78}$ and clinical series ${ }^{9}{ }^{10}$ suggested an increased risk of lung cancer in HIV+ patients, and again confirmed its worse prognosis. However, not all such studies noted such an increase. ${ }^{11-16}$ Then, in 1996, mortality due to AIDS began to decrease sharply in industrialised countries following the introduction of highly active antiretroviral treatment (HAART). ${ }^{17}$ However, this was accompanied by an increase in the proportion of deaths due to non-AIDS defining malignancies including lung cancer. ${ }^{18} 19$ Moreover, in two recent epidemiological studies, lung cancer was the leading fatal non-AIDS defining malignancy, ${ }^{19}{ }^{20}$ tending to confirm the suspicion of an increased risk of lung cancer in the HIV+ population. ${ }^{18-21}$ In fact, lung cancer now accounts for three times more cancer deaths than non-Hodgkin's lymphoma, 11-40\% of deaths from non-AIDS defining cancers, and 1.6-4.25\% of all deaths in HIV+ patients. ${ }^{6}{ }^{18} 22$

This review examines current epidemiological data and factors which might explain this putative increased risk of lung cancer in the HIV+ population, as well as the clinical, radiological, pathological, prognostic, and therapeutic features in this setting, particularly in the HAART era.

\section{SEARCH STRATEGY}

The search strategy was conducted using PubMed, without limitation of date, to identify potentially relevant articles using the following keyword terms: (1) for clinical, radiological, pathological, and therapeutic aspects: [lung cancer or lung carcinoma] and [HIV or AIDS]; (2) for epidemiological and mortality aspects: [AIDS or HIV] and [lung cancer or lung carcinoma or non-AIDS defining malignancy] and [epidemiology or mortality]; (3) we also looked for [genotoxicity or carcinogenotoxicity] and [anti-retroviral drugs]. However, our research was limited to articles published in English, with an abstract available, and concerning studies in humans. Papers dealing with Hodgkin's and non-Hodgkin's lymphoma and Kaposi's sarcoma were excluded from the analysis, except for data on interactions between HAART and chemotherapy and the impact of chemotherapy on HIV plasma viral load and CD4 cell counts. Original papers were mainly cited, with minimal use of case reports and general reviews.

\section{EPIDEMIOLOGY}

Risk for lung cancer in the HIV+ population The possibility of an increased risk was initially raised by epidemiological studies using the standardised incidence ratio (SIR), the ratio of the observed incidence of lung cancer in the HIV+ study population to the expected incidence in the same general lung cancer population. The expected incidence is calculated from the

Abbreviations: HAART, highly active antiretroviral treatment; IVDU, intravenous drug user; $\mathrm{LOH}$, loss of heterozygosity; PS, performance status; SIR, standardised incidence ratio 
Table 1 Standardised incidence ratio (SIR) of lung cancer in the HIV infected population according to sex and HIV transmission group

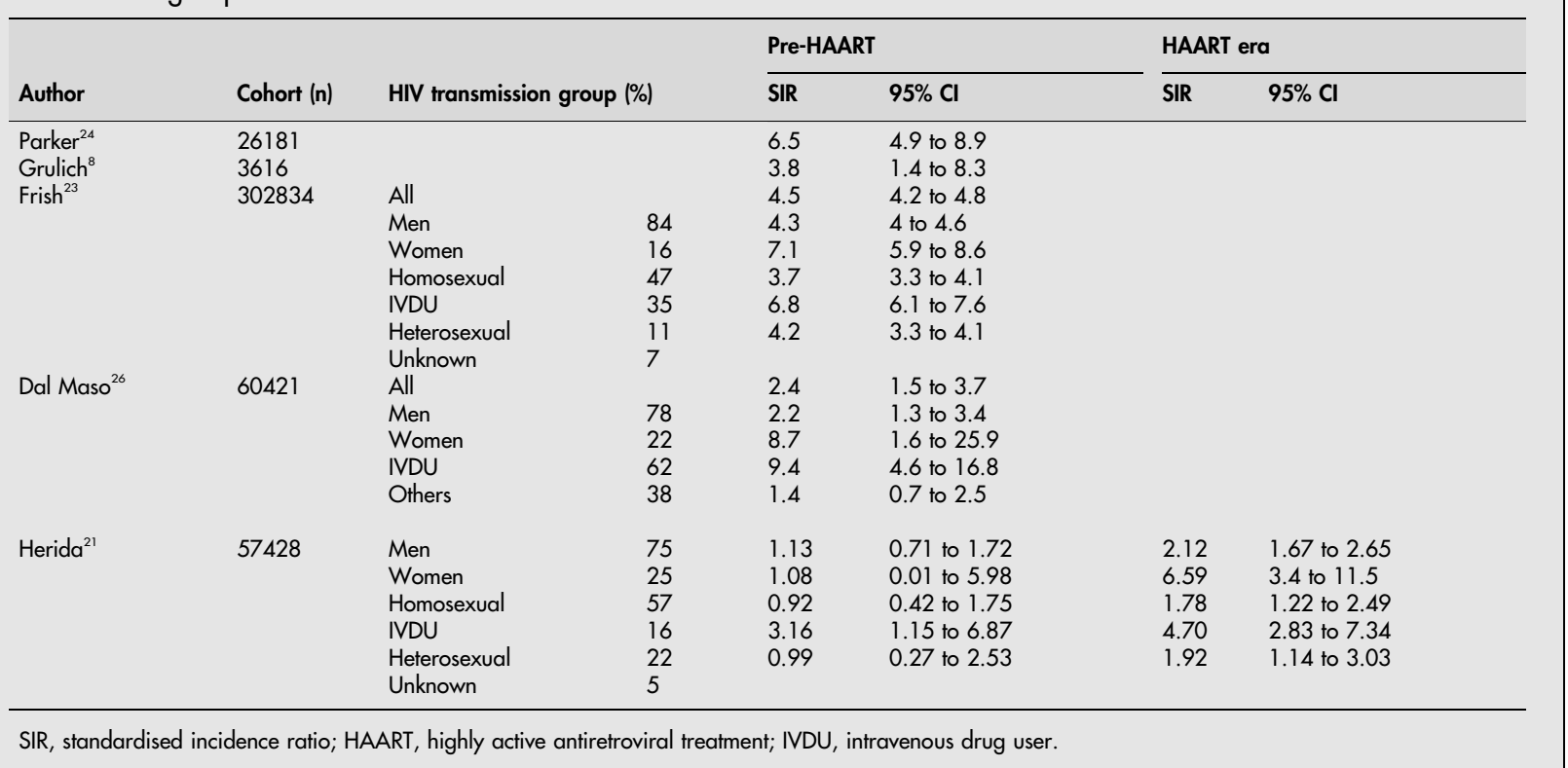

observed incidence of lung cancer in the general population (assumed to be HIV-), assuming that the HIV+ population is exposed to the same known risk factors for lung cancer as the general population of similar age and same sex. The incidence of lung cancer in the general population is obtained from regional or national cancer registries.

The SIR for lung cancer in the HIV+ population was determined in studies carried out either before the HAART era (pre-1996) ${ }^{83-26}$ or both before and during the HAART era (table 1). ${ }^{20} 21{ }^{27}$ All five studies from the pre-HAART period ${ }^{83-26}$ showed an increased risk of lung cancer in the HIV+ population (SIR >1) but, surprisingly, two studies covering both periods ${ }^{20}{ }^{21}$ showed an even higher risk of lung cancer in the HIV+ population during the HAART period.

\section{Pre-HAART studies}

Data on cancers in 302834 AIDS patients diagnosed from 1978 to 1996 in 11 regions of the USA showed that lung cancer was the most frequent non-AIDS defining malignancy with a SIR of 4.5. The risk was higher among women $(\mathrm{SIR}=7.1)$ than men $(\mathrm{SIR}=4.3) .{ }^{23}$ Similarly, in two other studies the SIR for lung cancer was 6.5 among 26181 American patients with AIDS (35/36 (97\%) were men), ${ }^{24}$ and 3.8 in 3616 Australian patients with AIDS diagnosed during 1980-93. ${ }^{8}$ Finally, in one study performed in Italy the SIR for lung cancer was 2.4 in 60421 patients with AIDS diagnosed during 1985-98. However, the risks differed between men and women ( SIR $=2.2 v 8.7)$ and between intravenous drug users (IVDUs) and other transmission groups ( $\mathrm{SIR}=9.4 \mathrm{v}$ $1.4) \cdot{ }^{26}$

\section{Pre-HAART $v$ HAART studies}

A prospective study of 77025 HIV+ patients treated in France in the pre-HAART period (1992-5) compared with the HAART period (1996-9) showed that the risk of lung cancer in the HIV+ population during the pre-HAART period was not different from that in the general population, except in the subgroup of male IVDUs (SIR =3.16), although the number of such patients was small $(\mathrm{n}=6) \cdot{ }^{21}$ In contrast, during the HAART period, the risk of lung cancer was higher in the HIV+ population than in the general population. The risk differed according to the HIV transmission route and $\operatorname{sex}(\mathrm{SIR}=1.78$ for homosexuals, 1.92 for heterosexuals, 4.70 for IVDUs, 2.12 for men, and 6.59 for women). ${ }^{21}$

Similarly, a study in England found that the incidence of lung cancer was $0.8 / 100000 \mathrm{HIV}+$ patients $(n=2)$ in the preHAART period, the same as the general population in 1996 $(0.75 / 100000)$, but $6.7 / 100000 \mathrm{HIV}+$ patients $(\mathrm{n}=9)$ in the HAART period resulting in a relative risk of $8.93 .^{20}$ The risk of lung cancer was also higher in $7304 \mathrm{HIV}+$ patients in a Swiss HIV cohort study than in the general population ( SIR $=3.2$ ). However, there was no clear impact of HAART on the SIR for lung cancer in HIV+ patients. ${ }^{27}$

\section{FACTORS WHICH MAY EXPLAIN THE RECENT INCREASED RISK OF LUNG CANCER IN THE HIV+ POPULATION \\ Smoking}

The increased risk of lung cancer might reflect different smoking habits, as surveys suggest that HIV+ subjects smoke more than the general population. ${ }^{28}$ One study found more smokers among 274 HIV+ patients than in 1038 HIVsubjects of similar age $(57 \% \vee 33 \%, \mathrm{p}<0.001) .{ }^{29}$ In four epidemiological studies ${ }^{21} 232627$ the risk of lung cancer in the HIV+ population was highest among IVDUs, a group also known to be heavy smokers (table 1 ). ${ }^{30}$ In one study, HIV+ lung cancer patients smoked 40 cigarettes/day compared with 20/day in HIV- patients, although the duration of exposure was shorter in the former group. ${ }^{4}$ Finally, in South Africa where the incidence of HIV+/AIDS is high but smoking low, there was no increased risk of lung cancer ${ }^{31}$ and, in one study, no cases of lung cancer were found in HIV+ patients who did not smoke. ${ }^{32}$

However, lung cancer cases still remained 2.5 times higher than expected, even assuming that all cohort patients were smokers. ${ }^{10}$ This led to the opinion that smoking was not the only factor responsible for the rise seen. Furthermore, the most common type of lung cancer in HIV+ patients is adenocarcinoma, the subtype least strongly associated with smoking (see below). The increased risk of lung cancer in the HIV+ population might therefore be explained by heavier smoking, even if other factors may also be causative. 
Table 2 Characteristics of $\mathrm{HIV}+$ patients with lung cancer

\begin{tabular}{|c|c|c|c|c|c|c|c|}
\hline Characteristics & Karp $^{10}$ & Sridhar $^{42}$ & Vyzula ${ }^{5}$ & Tirelli $^{4}$ & Alshafie $^{61}$ & Lavole $^{45}$ & Spano ${ }^{62}$ \\
\hline No of patients & 7 & 19 & 16 & 36 & 11 & 44 & 22 \\
\hline Year & 1983-91 & 1986-91 & $1988-93$ & 1986-98 & 1990-94 & 1987-2001 & 1993-2002 \\
\hline Median age & 38 & 48 & 44 & 38 & 50 & 42 & 45 \\
\hline Males (\%) & 86 & 100 & 94 & 89 & 82 & 93 & 86 \\
\hline Smokers (\%) & 100 & 93 & 100 & 94 & 90 & 100 & 95 \\
\hline Pack-years & 35 & 60 & 30 & $40 \mathrm{cig} / \mathrm{d}$ & - & 30 & - \\
\hline \multicolumn{8}{|l|}{ HIV transmission route (\%) } \\
\hline Homosexual & - & 32 & 38 & 17 & 0 & 33 & 45 \\
\hline IVDU & 100 & 21 & 56 & 69 & 82 & 44 & 23 \\
\hline Heterosexual & - & 26 & 6 & 14 & - & 7 & 32 \\
\hline Other & - & 21 & - & - & 18 & 16 & - \\
\hline PS > $2(\%)$ & - & 37 & 69 & 43 & - & 71 & 69 \\
\hline CD4+ <200 (\%) & - & 53 & 54 & 28 & 30 & 43 & 9 \\
\hline CD4+ (mean) & - & 121 & 184 & 150 & 200 & 250 & 364 \\
\hline AIDS (\%) & - & 50 & 25 & 20 & - & 33 & 32 \\
\hline
\end{tabular}

\section{HIV related factors}

The oncogenic role of HIV is controversial. In vitro studies have shown that the tat (transactivator of transcription) gene product from HIV can increase the expression of the protooncogenes c-myc, c-fos, and c-jun and downregulate the tumour suppressor gene p53 in lung adenocarcinoma cell lines. ${ }^{33}$ However, the absence of integrated HIV genomes in microdissected tumour samples from lung cancer patients argues against this hypothesis. ${ }^{34}$ Similarly, the lack of human papilloma virus sequences in HIV associated lung cancer argues against its aetiological role, ${ }^{34}$ although the virus has been implicated in anal and cervical cancer in the HIV+ population, in a subset with sporadic lung cancer, ${ }^{35}$ and in non-smoking Asian women with lung adenocarcinoma. ${ }^{36}{ }^{37}$

It is difficult to determine if chronic immunosuppression is a risk factor for lung cancer in the HIV+ population, as epidemiological studies do not analyse the lung cancer risk according to CD4+ lymphocyte count at diagnosis of lung cancer or during the interval between diagnosis of HIV infection and lung cancer. ${ }^{8212438} 39$ However, several studies have suggested that the risk increases with increasing immunosuppression. ${ }^{16} 384041$ In two studies a significantly increased risk was observed in men (although not women) with progression from pre-AIDS to AIDS, ${ }^{40}$ and in AIDS compared with only HIV+ patients. ${ }^{41}$ In two other studies lung cancer was significantly more frequent in the period surrounding an AIDS diagnosis (6 months to 2 years after diagnosis in the first and 4-27 months after diagnosis in the second) than in the pre-AIDS period. ${ }^{16}{ }^{38}$ Some studies from the pre-HAART era suggest, however, that lung cancer appears relatively early in the course of HIV infection. ${ }^{9} 1042$ HIV+ patients with lung cancer do not seem to be particularly immunosuppressed, having a median CD4+ count at lung cancer diagnosis of $250 / \mu \mathrm{l} ; 50 \%$ had counts $>200 / \mu \mathrm{l}$ and $\sim 60 \%$ had yet to develop AIDS. ${ }^{5}{ }^{43} 44$ In addition, the degree of immunosuppression was found to be less in the HAART period than in the pre-HAART period in two recent epidemiological studies. ${ }^{2021}$ Nonetheless, the risk of lung cancer remains higher in the HAART period, ${ }^{18}{ }^{19}$ both in men and women, ${ }^{21}$ and the cause of this paradox remains an open question.

\section{Increased susceptibility to carcinogens}

Evidence is lacking that HIV+ patients are more susceptible to carcinogens contained in tobacco smoke. Indeed, studies have shown that HIV+ patients with lung cancer smoke less, as much as, or more than lung cancer patients with undetermined HIV status (table 2). ${ }^{10} 4245$

The possible role of genomic instability in the increased lung cancer risk among HIV+ patients is suggested by a study of 16 polymorphic markers on eight chromosome arms frequently deleted in lung cancer. ${ }^{34}$ Tumour samples from 11 HIV+ patients with lung cancer and 35 patients who were assumed to be HIV - showed that the two groups did not differ with regard to the frequency of loss of heterozygosity $(\mathrm{LOH})$ or type of $\mathrm{LOH}$, except at two loci. In the HIV+ patients LOH was more frequent on chromosome arm 5 q22 (86\% $v$ $39 \% ; \mathrm{p}=0.007)$ and less frequent at 3pl4.2 (FHIT gene) $(25 \%$ $v 77 \% ; \mathrm{p}=0.03)$. The significance of these differences, if any, is unknown.

However, microsatellite alteration was six times more frequent in the HIV+ patients $(0.18 v 0.03 ; \mathrm{p}<0.001)$ and was widespread. $^{34}$ Moreover, no microsatellite alteration was found in normal tissues, arguing against factors affecting DNA repair such as HIV, antiretroviral drugs, chronic immune deficiency, chemotherapy, or radiotherapy. It could not be determined whether microsatellite alteration was an early or late event, but the authors felt it could have an important role in lung cancer development. ${ }^{34}$

Two nucleoside analogue reverse transcriptase inhibitors, zidovudine (AZT) and lamivudine-part of the HAART regime-are DNA replication chain terminators and can be genotoxic. In animal models, AZT in particular is a moderately strong transplacental carcinogen for up to 2 years after birth and can be incorporated into the DNA of many fetal organs. This damage is dose related and can be significant. In some organs telomeres are shortened. In human infant cord blood the combination of AZT and lamivudine produces DNA damage. ${ }^{46}$ Thus, although not yet shown to be carcinogenic in humans, these two drugs could conceivably act as co-carcinogens, along with tobacco smoke, in causing lung cancer.

\section{Risk of lung cancer in the HAART era}

There are conflicting data as to whether patients developing lung cancer since the introduction of HAART are older, which could account for some of the increase in the incidence of lung cancer. In HIV+/AIDS patients $\geqslant 60$ years of age, twice as many patients with lung cancer were observed $(n=105)$ as were expected $(\mathrm{n}=54.5)$, with a relative risk of $1.9{ }^{47} \mathrm{In}$ another study men with non-AIDS defining cancers were 3 years older in the HAART era. ${ }^{21}$

Two other factors might also explain the difference in lung cancer risk between the pre-HAART and HAART periods. Firstly, the increase in life expectancy conferred by HAART (currently more than 5 years) ${ }^{17}$ might explain the onset of smoking related diseases such as lung cancer, the risk of which increases with pack-years smoked. The rate of lung cancer increased from $1 \%$ to $6 \%$ among HIV+ patients admitted to a French chest unit in $1993-9(p=0.004)$, while 
the number of HIV+ patients admitted to hospital for all causes fell by $\sim 50 \%$ during that period. ${ }^{48}$ Secondly, the decline in deaths from AIDS might lead to the development of causes linked to other competing risks such as smoking. ${ }^{17}$ For example, mortality due to non-AIDS malignancies rose from $6.4 \%$ in 1994 to $10.9 \%$ in 1998 in San Francisco, ${ }^{18}$ with lung cancer being the leading cause of non-AIDS cancer deaths. However, the absolute number of lung cancer deaths remained about the same during the 4 year period. ${ }^{18} 19$

The even greater increase in risk among HIV+ women during the HAART period is of interest, ${ }^{17}{ }^{19}$ although one group felt that the SIR of lung cancer among HIV+ women may have been overestimated. ${ }^{21}$ Over-representation of IVDUs (a group usually comprised of heavy smokers) among HIV+ women with lung cancer may be one explanation. In one study $50 \%$ of HIV+ women were IVDUs ${ }^{23}$ and in another the percentage of IVDUs in HIV+ women with non-AIDS defining cancers rose from $20 \%$ to $30 \%$ between the preHAART and HAART periods. ${ }^{21}$ Furthermore, in an American women cohort study including 2059 HIV+ patients and 569 HIV uninfected at-risk women enrolled between 1994 and 1996, the SIR for lung cancer was 6.3 (95\% CI 2.7 to 11.3 , $\mathrm{p}<0.0001$ ) compared with the surveillance, epidemiology, and end results (SEER) rates and was not different between the pre-HAART and HAART periods. Interestingly, the SIR for lung cancer was similarly increased $(6.9,95 \%$ CI 0.8 to 19.3 , $\mathrm{p}<0.07$ ) in HIV - at-risk women compared with the general population, which suggests that the high rates of lung cancer are not associated with HIV infection. Instead, they are probably attributable to high rates of cigarette smoking found in both HIV+ $(57.1 \%)$ and HIV - at-risk women $(65.7 \%) .{ }^{49}$ On the other hand, the far higher SIR for lung cancer in HIV+ women relative to men in the HAART period could reflect the higher susceptibility of women to lung cancer with the same degree of tobacco exposure..$^{50-52}$

Current epidemiological data therefore seem to show an increase in the risk of lung cancer in the HIV+ population, a group more likely than the general population to smoke. ${ }^{29}$ This risk appears to be particularly high among IVDUs and women. Any data on the risk of lung cancer in women IVDUs who are smokers (both HIV+ and HIV-) would be of interest. The role of risk factors other than smoking (such as particular susceptibility to tobacco carcinogens, severity and duration of immunosuppression, viral co-infection, possible mutagenicity of antiretroviral drugs ${ }^{53}{ }^{54}$ ) remains to be investigated.

\section{DEMOGRAPHIC, CLINICAL, AND RADIOLOGICAL CHARACTERISTICS}

The first cases of lung cancer in HIV+ patients were reported in 1984. ${ }^{1}$ Since then, case reports, ${ }^{55-57}$ descriptive reviews, ${ }^{10}{ }^{58-60}$ and case-control series have been published. ${ }^{4542456162}$ It is noteworthy that the control groups in case-control series consisted of subjects with unknown HIV status rather than exclusively HIV - subjects. This bias may minimise observed differences between the HIV+ and control populations, particularly if the control group is age matched with the HIV+ population.

Lung cancer has been reported to occur at a significantly younger age among HIV+ patients than in the general lung cancer population, ${ }^{4542456263}$ especially in a comparative study in which the subjects were not matched for age (mean 45 years (range 38-49) $v 62$ years (range 36-75)). ${ }^{6}$

Men are significantly more at risk than women, with a male:female sex ratio of 9-10:1. ${ }^{454246162}$ This reflects the epidemiology of lung cancer and HIV/AIDS, both of which have affected men more than women for reasons linked to the respective risk factors. Male predominance may become less marked in the future, as suggested by a recent epidemiological study in which SIR for lung cancer was higher in HIV+ women than in men. ${ }^{21}$ This trend may arise from the increase in female smokers in the general population and a narrowing of the male:female ratio in the HIV+ population. ${ }^{64}$ The proportion of smokers is high (>85\%) among HIV+ patients with lung cancer, and in HIV+ IVDUs $(96 \%),{ }^{27}$ but similar to controls of similar age ${ }^{42}{ }^{45}{ }^{61}$ Duration of smoking and extent of tobacco used are also similar, with both parameters tending to be higher in studies involving large proportions of HIV+ IVDUs (table 2)..$^{561}$

The distribution of the different modes of HIV transmission in patients with lung cancer is similar to that of the general HIV+ population. The degree of immune deficiency is generally moderate at the time of lung cancer diagnosis with a mean CD4+ cell count of $250 / \mathrm{mm}^{3}$ (range $121-364 / \mathrm{mm}^{3}$ ). The proportion of patients with CD4+ cell counts $<200 / \mathrm{mm}^{3}$ varies widely from $9 \%$ to $54 \% .^{45323345}$ At the time of diagnosis of lung cancer in HIV+ patients, 25-50\% already have known AIDS. However, this proportion has tended to be lower in more recent series. ${ }^{62}$

Most patients are symptomatic at diagnosis, reflecting extensive disease. Indeed, lung cancer is diagnosed when locally advanced or metastatic (stage IIIB-IV) in $75-90 \%$ of HIV+ patients, similar to that in age matched lung cancer control groups. ${ }^{4}{ }^{42} 4561$ Symptoms are variable, non-specific, and usually multiple. ${ }^{1061}$ Respiratory symptoms include cough $(40-86 \%)$, chest pain $(25-57 \%)$, dyspnoea (10-57\%), and haemoptysis (10-29\%). Their frequency and distribution do not differ from those in age matched lung cancer controls, ${ }^{1061}$ and the same is true of non-respiratory symptoms. Performance status (PS) $\geqslant 2$ was $37-57 \%$ before $1996^{4}{ }^{5}$ but $\sim 30 \%$ subsequently..$^{62}$ The general health status of HIV+ patients with lung cancer appears to be less than that of HIV indeterminate controls $(29 \% v 7 \%, \mathrm{p}=0.01$ in one series $\left.^{45}\right)$.

A few small studies have examined the radiological features in HIV+ patients with lung cancer. ${ }^{10}{ }^{48-51}$ Most primaries were $\mathrm{T} 2{ }^{48}$ but, in HIV+ patients with one or more nodules on the CT scan, only $4 \%$ had lung cancer. ${ }^{65}$ The most common finding is a mass (80-100\%) measuring $\sim 4.5 \mathrm{~cm}$

Table 3 Histological distribution of lung cancer in HIV+ patients

\begin{tabular}{|c|c|c|c|c|c|c|}
\hline & $\begin{array}{l}\text { Sridhar }{ }^{42} \\
(n=19)\end{array}$ & $\begin{array}{l}\text { Vyzula } \\
(\mathrm{n}=16)\end{array}$ & $\begin{array}{l}\text { Tirelli }^{4} \\
(n=36)\end{array}$ & $\begin{array}{l}\text { Alshafie }^{61} \\
(n=11)\end{array}$ & $\begin{array}{l}\text { Lavole }^{45} \\
(n=44)\end{array}$ & $\begin{array}{l}\text { Spano } \\
\text { ( } \mathrm{n}=22)\end{array}$ \\
\hline \multicolumn{7}{|l|}{ Histology, n (\%) } \\
\hline Adenocarcinoma & $5(31)$ & $8(50)$ & $14(39)$ & $5(46)$ & $23(52)$ & $8(36.5)$ \\
\hline Squamous cell & $6(37)$ & $3(19)$ & $12(33)$ & $4(36)$ & $10(23)$ & $11(50)$ \\
\hline Large cell & $2(13)$ & $3(19)$ & $5(14)$ & $1(9)$ & $5(11)$ & $1(4.5)$ \\
\hline Other & $0(0)$ & $0(0)$ & $0(0)$ & $0(0)$ & $0(0)$ & $1(4.5)$ \\
\hline Small cell & $1(6)$ & $2(12)$ & $5(14)$ & $1(9)$ & $6(14)$ & $1(4.5)$ \\
\hline \multicolumn{7}{|l|}{ Stage (\%) } \\
\hline 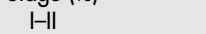 & 21 & 19 & 16 & 10 & 23 & 25 \\
\hline III-IV & 79 & 81 & 84 & 90 & 77 & 75 \\
\hline
\end{tabular}


Table 4 Comparison of survival rates in HIV+ and HIV indeterminate patients with lung cancer

\begin{tabular}{lllllll}
\hline Survival & $\begin{array}{l}\text { Karp }^{10 *} \\
\text { HIV+/HIV? }\end{array}$ & $\begin{array}{l}\text { Sridhar }^{42} \\
\text { HIV+/HIV? }\end{array}$ & $\begin{array}{l}\text { Vyzula }^{5} \dagger \\
\text { HIV+/HIV? }\end{array}$ & $\begin{array}{l}\text { Tirelli }^{4} \\
\text { HIV+/HIV? }\end{array}$ & $\begin{array}{l}\text { Alshafie }^{61} \\
\text { HIV+/HIV? }\end{array}$ & $\begin{array}{l}\text { Lavole }^{45} \\
\text { HIV+/HIV? }\end{array}$ \\
\hline $\begin{array}{l}\text { Median (months) } \\
\text { \% alive at 1 year }\end{array}$ & $1 / 5$ & $3 / 10$ & $8 / 12.5$ & $5 / 10$ & $4 / 7$ & $9 / 11$ \\
\% alive at 2 years & - & $0 / 32$ & $10 / 50$ & $10 / 48$ & $0 / 20$ & $15 / 41$ \\
p value & $<0.01$ & $0 / 0$ & $0 / 18$ & $0 / 25$ & $0 / 8$ & $11 / 22$ \\
HIV+/HIV- & 0.002 & 0.0035 & 0.0001 & $<0.003$ & 0.01 \\
\hline
\end{tabular}

*Stage IV only compared.

†Males only analysed.

$\ddagger$ Stages IIIB/IV only.

(range 2.0-8.0), more often peripheral (11/15) than central $(4 / 15)$, and located in the upper lobes $(10 / 15) \cdot{ }^{65-69}$ When the lung cancer was peripheral, more patients (15/18) had a history of tuberculosis or Pneumocystis jirovesi pneumonia than did those with a central lesion $(3 / 11, p=0.005)$ in one preHAART study. ${ }^{69}$ One study showed a higher frequency of mediastinal adenopathy $(6 / 7 v 7 / 14)$ and pleural effusion (4/7 $v$ 4/14) in HIV+ patients with adenocarcinoma type lung cancer than in HIV- patients with adenocarcinoma, but these differences were not statistically significant. ${ }^{10}$ Other studies found that extensive pleural disease in the absence of a primary was not uncommon. ${ }^{68} 70$

\section{Pathological findings}

Non-small cell lung cancer (NSCLC) represents $86-94 \%$ of HIV+ patients with lung cancer while small cell carcinoma has been reported in only $5-13 \% .^{71}$ Of all HIV+ cases with NSCLC, adenocarcinoma represents $31-50 \%$, squamous cell carcinoma 19-52\%, and large cell carcinoma 9-19\% (table 3). ${ }^{454246162}$ Adenocarcinoma was the histological type most frequently observed in all but two studies, ${ }^{42}{ }^{62}$ but otherwise the distribution of the histological types is similar to age matched lung cancer control groups. ${ }^{45} 424861$ Thus, the predominance of adenocarcinoma in HIV+ patients reflects general changes in the distribution of the histological types of lung cancer. Adenocarcinoma superseded squamous cell carcinoma in the general population of the USA in the $1990 \mathrm{~s}^{72}$ and, subsequently, in other industrialised countries. ${ }^{73}$

\section{Prognostic factors}

The prognosis of lung cancer was poorer in HIV+ patients than in subjects with undetermined HIV serostatus in all case-control studies published to date (table 4), ${ }^{45} 10424561$ with one exception. ${ }^{32}$ However, in this latter study the median survival of the control group was particularly low (4 months) compared with that in other studies also matched for age (7-11 months). ${ }^{52} 45$ Regardless of TNM stage, median survival time among HIV+ patients with lung cancer is 4.5 months (range 3-9) compared with 10 months (range 4-12.5) in age matched HIV-controls (table 4). ${ }^{5} 324245$ The 1 year survival rate is about $10 \%$ (range $0-15 \%$ ) among HIV+ patients and about $40 \%$ (range $20-50 \%$ ) in controls. In most published studies no HIV+ patients were living 2 years after diagnosis compared with $0-25 \%$ of controls (table 4 ). However, a recent study found a 2 year survival rate of $10 \%$ both in the periods 1990-1995 and 1996-2000. Unfortunately, 24 month survival was the same in both the pre-HAART and HAART periods for those with AIDS and lung cancer $(10 \%) \cdot{ }^{74}$ Finally, in older series death tended to be linked to HIV infection $(65 \%)^{61}$ while in more recent series it is mainly due to lung cancer itself $(75-88 \%) .^{432} 4562$

Very few data are available on prognostic factors in HIV+ patients with lung cancer. In a single health system, in an historical cohort study of 1155 lung cancer patients, the effect of 56 co-morbidities including HIV+/AIDS on survival was evaluated in univariate and multivariate models adjusted for recognised prognostic factors (age, sex, smoking status,

Table 5 Surgical outcomes of HIV+ patients with lung cancer

\begin{tabular}{|c|c|c|c|c|c|c|}
\hline Author & Patient & CD4+ & Stage & Treatment & Survival (months) & Complications \\
\hline \multirow[t]{6}{*}{ Spano $o^{62 *}$} & 1 & 390 & IIIA & $S$ & 11 & 0 \\
\hline & 2 & 570 & IA & $S$ & 36 & 0 \\
\hline & 3 & 420 & IB & $\mathrm{s}$ & 72 (alive) & 0 \\
\hline & 4 & 343 & $\|$ & CT-S-RT & 17 (alive) & 0 \\
\hline & 5 & 200 & $\|$ & CT-S & 8 & 0 \\
\hline & 6 & 410 & IB & $S$ & 3 (alive) & 0 \\
\hline \multirow[t]{2}{*}{ Massera $^{78}$} & 7 & $<200$ & IIIA & $S$ & 12 & 0 \\
\hline & 8 & $<200$ & $\| B$ & $S$ & 20 (alive) & 0 \\
\hline \multirow[t]{3}{*}{ Sridhar ${ }^{42}$} & 9 & 19 & IA & $\mathrm{s}$ & 5 & - \\
\hline & 10 & 524 & IA & $S$ & 3 & - \\
\hline & 11 & 99 & IA & S & 12 (alive) & - \\
\hline \multirow[t]{2}{*}{ Vyzula ${ }^{5}$} & 12 & - & 1 & $\mathrm{~s}$ & 9 & 0 \\
\hline & 13 & 371 & I & $s$ & 19 & 0 \\
\hline \multirow[t]{8}{*}{ Lavole $^{45}$} & 14 & 653 & I & $\mathrm{s}$ & 39 & 0 \\
\hline & 15 & 369 & IIIB & $\mathrm{s}$ & 1.5 & Infection, death \\
\hline & 16 & 350 & IIIA & $\mathrm{s}$ & 31 & 0 \\
\hline & 17 & 550 & $\|$ & $\mathrm{s}$ & 8 & 0 \\
\hline & 18 & 439 & IIIA & CT-S & 22 & 0 \\
\hline & 19 & 407 & IA & CT-S & 9 & 0 \\
\hline & 20 & 280 & IIIA & CT-S & 28 & 0 \\
\hline & 21 & $<200$ & IA & Lobectomy & 5 & - \\
\hline \multirow{3}{*}{ Thurer ${ }^{77}$} & 22 & $<200$ & IA & Lobectomy & 5 & - \\
\hline & 23 & $<200$ & IA & Lobectomy & 3.5 & - \\
\hline & 24 & 963 & IA & Wedge & 12 (alive) & 0 \\
\hline
\end{tabular}

S, surgery; CT-S, chemotherapy following surgery; CT-S-RT, chemotherapy, surgery and radiotherapy.

*Five patients had lobectomy, one had a pneumonectomy. 
histology, and stage).$^{75}$ The prevalence of AIDS/HIV patients in the cohort study was $0.7 \%$; the median survival of HIV+ patients with lung cancer was 4.8 months compared with 10.3 months for the entire study population (hazard ratio $(\mathrm{HR})=2.33, \mathrm{p}=0.002)$. HIV/AIDS was a predictor of survival adjusted for baseline co-morbidities $(\mathrm{HR}=4.77, \mathrm{p}=0.0001)$, other co-morbidities $(\mathrm{HR}=3.69, \mathrm{p}=0.0008)$, and treatments $(\mathrm{HR}=3.76, \mathrm{p}=0.0006)$. Furthermore, the HR for AIDS/HIV consistently predicted shortened survival in both early (I-II) and advanced stages (III-IV). Although, the HR for HIV/AIDS was not explained by treatment, a moderate amount (15$30 \%)$ of the hazard was explained by their associations with other co-morbidities. ${ }^{75}$ In a retrospective case-control study of patients with NSCLC (38 HIV+ and 38 age matched patients of undetermined HIV status) reported in 2003 (not yet published in full), ${ }^{45}$ TNM stage, PS, and HIV status were the independent prognostic factors. TNM distribution was identical in the two groups and did not explain the difference in survival. However, the higher proportion of patients with PS $\geqslant 2$ in the HIV+ group with lung cancer might have contributed to their poorer survival. The reasons why HIV status is associated with poorer outcome are unclear. ${ }^{45}{ }^{75}{ }^{76} \mathrm{In}$ particular, CD4+ cell count and AIDS status at lung cancer diagnosis do not seem to influence prognosis, ${ }^{27} 5960$ nor is there a correlation between lung cancer stage and CD4 counts. ${ }^{42}$ HIV infection was responsible for death in $<30 \%$ of cases of lung cancer in the most recent series in which patients were less severely immunosuppressed than in earlier studies. $^{32} 457576$

The general consensus therefore seems to be that these patients are apt to be young, male, heavy smokers, have peripheral adenocarcinomas, advanced disease at presentation, a poor PS, tolerate radiation and medical treatment poorly, and have a poor prognosis no matter what the treatment.

\section{TREATMENT}

Data on the management of HIV+ patients with lung cancer come mainly from the abovementioned case-control series and case reports describing adverse effects. There are no published prospective clinical trials assessing efficacy and toxicity of chemotherapy regimens, used either alone or combined with radiotherapy.

\section{Surgery}

Data on the surgical treatment of HIV+ patients with lung cancer are summarised in table $5 .^{54245627778}$ Most patients do not have a low CD4+ cell count and are, in fact, in good health, although PS is rarely reported. Postoperative complications are limited to one death due to infection among 18 patients. Survival data vary. Five of seven patients with stage IA disease included in two series and undergoing surgery died within 5 months. ${ }^{42} 77$ However, these studies were performed before the introduction of HAART and it is not known if the cause of death was due to HIV infection or tumour progression. In contrast, a recent report describing two patients with CD4+ cell counts $<200 \mathrm{~mm}^{3}$ had no postoperative complications and acceptable survival at 12 months (stage IIIA) and 20 months (stage IIB). ${ }^{78}$ Surgery should therefore be considered for localised or even locally advanced disease in patients with adequate pulmonary function and good general status, regardless of immune status.

\section{Chemotherapy}

The results of chemotherapy for HIV+ patients with lung cancer are few and imprecise. Chemotherapy has been used to treat metastatic disease, ${ }^{5242456162}$ but has also been used in combination with radiotherapy for locally advanced disease and perioperatively. ${ }^{40}{ }^{62}$ Its use seems less frequent in HIV+ patients with lung cancer than in controls with undetermined HIV status, whatever the disease stage, perhaps because of poorer PS. ${ }^{32}$ Treatment regimens are rarely described in detail. ${ }^{32}$ Efficacy and toxicity are difficult to analyse in the absence of clinical trials, but a recent study performed in England since the introduction of HAART suggested no difference in survival between HIV+ and HIVpatients (4 months in each group). ${ }^{32}$ Progression rates of 50 $70 \%$ have been reported after first line chemotherapy. ${ }^{45}$

Some authors suggest that poor results could be related to drug interactions and additive toxicity of cytotoxic and antiretroviral drugs. ${ }^{79}$ The non-nucleoside reverse transcriptase inhibitors efavirenz, delaviridine, and nevirapine are mainly metabolised by the cytochrome P450 system. However, protease inhibitors (especially ritonavir and indinavir) have a strong affinity for and inhibit cytochrome P450 $3 \mathrm{~A} 4{ }^{80}{ }^{81}$ which is also the main metabolic pathway used by ifosphamide, docetaxel, paclitaxel, irinotecan, vinca alkaloids, and etoposide. ${ }^{54}{ }^{82}$ Similarly, cultured tumour cells expressing P-gp have been shown to accumulate paclitaxel and vinblastine in the presence of certain protease inhibitors (saquinavir, ritonavir, and nelfinavir but not indinavir). ${ }^{83}$ All non-nucleoside reverse transcriptase inhibitors and most protease inhibitors inhibit P-gp, both improving drug sensitivity in vitro but also potentially increasing toxicity in vivo.

However, the clinical consequences of these pharmacological interactions have not been assessed in humans. Didanosine, stavudine, and zalcitabine have the same peripheral neurological toxicity ${ }^{82}{ }^{84}$ as regimens using a platinum with a taxane. ${ }^{85} 86$ Similarly, AZT bone marrow toxicity is enhanced when the drug is combined with anticancer chemotherapy. ${ }^{87}{ }^{88}$ Finally, in HAART treated patients receiving cyclophosphamide, doxorubicin, and etoposide

\begin{tabular}{|llll|}
\hline Table 6 & Toxicity of mediastinal radiotherapy in $13 \mathrm{HIV}+$ patients with lung cancer \\
\hline Authors & Patient & Oesophageal toxicity & Pulmonary toxicity \\
\hline Tirelli $^{4}$ & 1 & Grade 3 & 0 \\
& 2 & Grade 3 & 0 \\
& 3 & Grade 3 & 0 \\
& 4 & Grade 2 & 0 \\
Spano ${ }^{62}$ & 5 & 0 & 0 \\
& 6 & 0 & 0 \\
& 7 & 0 & 0 \\
Lavole $^{45}$ & 8 & 0 & 0 \\
& 9 & 0 & 0 \\
& 10 & 0 & 0 \\
& 11 & 0 & 0 \\
Toxic effect of grade 3/4. & 12 & Grade 3 & 0 \\
\hline
\end{tabular}


based chemotherapy for systemic AIDS related nonHodgkin's lymphoma, nadir neutrophil counts were significantly lower and grade 3-4 infections requiring admission to hospital were significantly more frequent $(48 \% \vee 25 \%$, $\mathrm{p}=0.0025$ ) in patients receiving protease inhibitors than in those receiving protease inhibitor sparing HAART regimens. ${ }^{89}$

The risk of opportunistic infection may also be considered in HIV+ patients with lung cancer receiving chemotherapy. In HAART treated patients receiving chemotherapy for nonHodgkin's lymphoma, the CD4+ cell count fell by 50\% but recovered within 1 month after chemotherapy. However, the percentage of CD4+ cells was unchanged throughout chemotherapy, as was the plasma HIV viral load. ${ }^{90} \mathrm{CD} 4+$ cell recovery is faster in these patients than in HIV- patients and in HIV+ patients treated by chemotherapy without HAART. ${ }^{90}{ }^{91}$ However, the impact of chemotherapy on the immunological status of HIV+ patients with lung cancer has not been evaluated, although opportunistic infections were rare in recent series. ${ }^{424562}$ No specific recommendations have been made on primary prophylaxis for opportunistic infections in HIV+ patients receiving chemotherapy. Together, these data suggest that the CD4+ cell count should be regularly monitored (every month) during and 1 month after completion of chemotherapy. Standard recommendations should be applicable in this setting. ${ }^{92}$ However, the indications for prophylaxis should be based on the absolute number rather than the percentage of CD4+ cells.

\section{Radiotherapy}

There are no data on the efficacy of thoracic radiotherapy on HIV+ patients with locally advanced or inoperable lung cancer. Toxicity data are summarised in table 6. Grade 3-4 toxicity was observed in four of 13 patients (31\%). ${ }^{4562}$ However, case reports have commented on severe oesophagitis and rapid stricture formation in patients receiving radiation therapy for lung cancer. ${ }^{93}{ }^{94}$ Severe adverse effects had previously been reported after thoracic radiotherapy for Kaposi's sarcoma in HIV+ patients. ${ }^{95-97}$ Possible causes include reduced mucosal repair capacities, ${ }^{93} 94{ }^{98}$ notably due to glutathione antioxidant deficiency, ${ }^{99}{ }^{100}$ and concurrent opportunistic oesophageal infections (such as Candida, herpes, cytomegalovirus, Cryptococcus) in those with AIDS. ${ }^{101} 102$

Available data suggest that HIV+ patients with lung cancer should be treated as recommended for the general population. However, it is advisable to avoid aggressive combinations carrying a high risk of chemotherapy toxicity and/or drug interactions. The use of conformal radiotherapy may limit the risk of adverse effects. ${ }^{103}$ Finally, close attention must be paid to adverse effects of chemotherapy and radiotherapy in this setting.

\section{CONCLUSIONS}

The risk of lung cancer, especially NSCLC, seems to be greater in the HIV+ population, but differences in smoking habits are probably not the only explanation. Histological types and stages are similar to that in the general lung cancer population of similar age, but the prognosis is poorer due, in part, to a lower PS at diagnosis. Treatment also appears to be more toxic and less effective, with a 1 year survival of only $10 \%$. These results should be improved. Smoking is the primary risk factor for lung cancer, and HIV+ patients (who tend to smoke more) develop lung cancer at an earlier age and after a shorter smoking history. However, the carcinogenic role of the antiretroviral nucleoside drugs-in particular, the combination of the nucleoside analogue reverse transcriptase inhibitors AZT and lamivudine and their interaction with smoking-needs to be examined. Patients must be informed of this increased risk and strongly encouraged to stop smoking. Screening with low dose spiral CT scanning should be considered in this high risk population. Peripheral adenocarcinoma tends to predominate, perhaps making surgery a more frequent option. Surgery seems as effective as in the general lung cancer population, while prospective studies of the efficacy and toxicity of chemotherapy and radiotherapy are needed to optimise patient management. The important question as to why the risk of lung cancer (especially NSCLC) in HIV+/AIDS patients is increased remains, as yet, not fully answered or completely understood.

\section{Authors' affiliations}

J Cadranel, A Lavolé, M Wislez, B Milleron, C Mayaud, Service de Pneumologie et Réanimation Respiratoire, AP-HP Hôpital Tenon, Paris, France

D Garfield, Department of Medicine, University of Colorado Health Sciences Center, Aurora, CO 80010, USA

David Garfield and Armelle Lavolé contributed equally to this work. Competing interests: none declared.

\section{REFERENCES}

1 Irwin LE, Begandy MK, Moore TM. Adenosquamous carcinoma of the lung and the acquired immunodeficiency syndrome. Ann Intern Med 1984; 100:158.

2 Monfardini S, Vaccher E, Pizzocaro G, et al. Unusual malignant tumours in 49 patients with HIV infection. AIDS 1989;3:449-52.

3 Braun MA, Killam DA, Remick SC, et al. Lung cancer in patients seropositive for human immunodeficiency virus. Radiology 1990;175:341-3.

4 Tirelli U, Spina M, Sandri S, et al. Lung carcinoma in 36 patients with human immunodeficiency virus infection. The Italian Cooperative Group on AIDS and Tumors. Cancer 2000;88:563-9.

5 Vyzula R, Remick SC. Lung cancer in patients with HIV-infection. Lung Cancer 1996;15:325-39.

6 Selik RM, Byers RH Jr, Dworkin MS. Trends in diseases reported on U.S. death certificates that mention HIV infection, 1987-1999. J Acquir Immune Defic Syndr 2002;29:378-87.

7 Johnson CC, Wilcosky T, Kvale P, et al. Cancer incidence among an HIVinfected cohort. Pulmonary Complications of HIV Infection Study Group. Am J Epidemiol 1997;146:470-5.

8 Grulich AE, Wan X, Law MG, et al. Risk of cancer in people with AIDS. AIDS 1999; 13:839-43.

9 Faire $A E$, Awe RJ. Lung cancer in association with human immunodeficiency virus infection. Cancer 1992;70:432-6.

10 Karp J, Profeta G, Marantz PR, et al. Lung cancer in patients with immunodeficiency syndrome. Chest 1993;103:410-3.

11 Biggar RJ, Burnett W, Mikl J, et al. Cancer among New York men at risk for acquired immunodeficiency syndrome. Int J Cancer 1989;43:979-85.

12 Lyter DW, Bryant J, Thackeray R, et al. Incidence of immunodeficiency virus related and non related malignancies a large cohort of homosexual men. J Clin Oncol 1995; 13:2540-6.

13 Chan TK, Aranda CP, Rom WN. Bronchogenic carcinoma in young patients at risk for acquired immunodeficiency syndrome. Chest 1993;103:862-4.

14 Cooksley CD, Hwang LY, Waller DK, et al. HIV-related malignancies: community-based study using linkage of cancer registry and HIV data. Int J STD AIDS 1999; 10:795-802.

15 International Collaboration on HIV and Cancer. Highly active antiretroviral therapy and incidence of cancer in human immunodeficiency virus-infected adults J Natl Cancer Inst 2000;92:1823-30.

16 Grulich AE, Li Y, McDonald A, et al. Rates of non-AIDS-defining cancers in people with HIV infection before and after AIDS diagnosis. AIDS 2002; 16:1155-61.

17 Mocroft A, Brettle R, Kirk O, et al. Changes in the cause of death among HIV positive subjects across Europe: results from the EuroSIDA study. AIDS 2002; 16:1663-71.

18 Lovie JK, Hsu LC, Osmond DH, et al. Trends in causes of death among persons with acquired immunodeficiency syndrome in the era of highly active antiretroviral therapy, San Francisco, 1994-1998. J Infect Dis 2002; 186:1023-7.

19 Bonnet F, Lewden C, May T, et al. Malignancy-related causes of death in human immunodeficiency virus-infected patients in the era of highly active antiretroviral therapy. Cancer 2004;101:317-24.

20 Bower $M$, Powles T, Nelson M, et al. HIV-related lung cancer in the era of highly active antiretroviral therapy. AIDS 2003;17:371-5.

21 Herida M, Mary-Krause M, Kaphan R, et al. Incidence of non-AIDS-defining cancers before and during the highly active antiretroviral therapy era in a cohort of human immunodeficiency virus-infected patients. J Clin Oncol 2003;21:3447-53.

22 Lewden C, Salmon D, Morlat P, et al. Causes of death among HIV-infected adults in the era of potent antiretroviral therapy: emerging role of hepatitis and cancers, persistent role of AIDS. Int J Epidemiol 2004;34:121-30. 
23 Frisch M, Biggar RJ, Engels EA, et al. Association of cancer with AIDS-related immunosuppression in adults. JAMA 2001;285:1736-45.

24 Parker MS, Leveno DM, Campbell TJ, et al. AIDS-related bronchogenic carcinoma: fact or fiction? Chest 1998:113:154-61.

25 Allardice GM, Hole DJ, Brewster DH, et al. Incidence of malignant neoplasms among HIV-infected persons in Scotland. Br I Cancer 2003;89:505-7.

26 Dal Maso L, Franceschi S, Polesel J, et al. Risk of cancer in persons with AIDS in Italy, 1985-1998. Br J Cancer 2003;89:94-100.

27 Clifford GM, Polesel J, Rickenbach M, et al. Cancer risk in the Swiss HIV Cohort Study: associations with immunodeficiency, smoking, and highly active antiretroviral therapy. I Natl Cancer Inst 2005;97:425-32.

28 Thompsen SC, Nanni C, Levine A. The stressors and stress of being HIVpositive. AIDS Care 1996:8:5-14.

29 Saves $M$, Chene G, Ducimetiere P, et al. Risk factors for coronary heart disease in patients treated for human immunodeficiency virus infection compared with the general population. Clin Infect Dis 2003;37:292-8.

30 Hughes JR. Treatment of smoking cessation in smokers with past alcohol/ drug problems. J Subst Abuse Treat 1993;10:181-7.

31 Sitas F, Pacella-Norman R, Carrara H, et al. The spectrum of HIV-1 related cancers in South Africa. Int J Cancer 2000;88:489-92.

32 Powles T, Thirwell C, Newsom-Davis T, et al. Does HIV adversely influence the outcome in advanced non-small-cell lung cancer in the era of HAART? Br J Cancer 2003;89:457-9.

33 El-Solh A, Kumar NM, Nair MP, et al. An RGD containing peptide from HIV1 tat (65-80) modulates protooncogene expression in human bronchoalveolar carcinoma cell line, A549. Immunol Invest 1997:26:351-70.

34 Wistuba II, Behrens C, Milchgrub S, et al. Comparison of molecular changes in lung cancers in HIV-positive and HIV-indeterminate subjects. JAMA 1998;279:1554-9.

35 Thomas P, De Lamballerie X, Garbe L, et al. Detection of human papillomavirus DNA in primary lung carcinoma by nested polymerase chain reaction. Cell Mol Biol 1995;8:1093-7.

36 Chen YC, Chiou HL, Sheu GT, et al. The association of human papillomavirus 16/18 infection with lung cancer among nonsmoking Taiwanese women. Cancer Res 2001:61:2799-803

37 Chen YW, Chen JH, Richard K, et al. Lung adenocarcinoma and human papillomavirus infection. Cancer Res 2004;101:1428-36.

38 Mbulaiteye SM, Biggar RJ, Goedert JJ, et al. Immune deficiency and risk for malignancy among persons with AIDS. J Acquir Immune Defic Syndr 2003:32:527-33

39 Cailhol J, Calatroni M-I, Roudiere L, et al. Increased incidence of lung neoplasms amolng $\mathrm{HIV}$-infected men and the need for improved prevention (letter). J Acquir Immune Defic Syndr 2003;34:247-8.

40 Gallagher B, Wang Z, Schymura MJ, et al. Cancer incidence in New York State acquired immunodeficiency syndrome patients. Am J Epidemiol $2001 ; 154: 544-56$

41 Newnham A, Harris J, Evans HS, et al. The risk of cancer in HIV-infected people in southeast England: a cohort study. Br J Cancer 2005;92:194-200.

42 Sridhar KS, Flores MR, Raub WA Jr, et al. Lung cancer in patients with human immunodeficiency virus infection compared with historic control subjects. Chest 1992;102:1704-8.

43 Mary-Krause $M$, Herida $M$, Costagliola D. HIV and the risk of lung cancer. $\mathrm{J}$ Clin Oncol 2004;22:1349-50.

44 Aaron SD, Warner E, Edelson JD. Bronchogenic carcinoma in patients seropositive for human immunodeficiency virus. Chest 1994;106:640-2.

45 Lavole A, Massiani MA, Wislez M, et al. Lung cancer in HIV-infected patients in the era of HAART: a case control study focusing on prognostic factors of survival. Lung Cancer 2003:41(Suppl 2):S3-314.

46 Poirier MC, Olivera OA, Walker DM, et al. Perinatal genotoxicity and carcinogenicity of anti-viral nucleoside analog drugs. Toxicol Appl Pharmacol 2004; 199:151-61.

47 Biggar RJ, Kirby KA, Atkinson J, et al. Cancer risk in elderly persons with HIV/AIDS. J Acquir Immune Defic Syndr 2004:36:861-8.

48 Dufour V, Wislez M, Lavole A, et al. Changes in the pattern of respiratory diseases necessitating hospitalization of HIV-infected patients since the advent of highly active antiretroviral therapy. Lung 2004;182:331-42.

49 Hessol NA, Seaberg EC, Preston-Martin S, et al. Cancer risk among participants in the women's interagency HIV study. J Acquir Immune Defic Syndr 2004;36:978-85

50 Ramalingam S, Pawlish K, Gadgeel S, et al. Lung cancer in young patients: analysis of a Surveillance, Epidemiology, and End Results database. J Clin Oncol 1998;16:651-7.

51 Zang EA, Wynder EL. Differences in lung cancer risk between men and women: examination of the evidence. J Natl Cancer Inst 1996;88:183-92.

52 Travis WD. Pathology of lung cancer. Clin Chest Med 2002;23:65-81.

53 Wutzler $P$, Thust $R$. Genetic risks of antiviral nucleoside analogues: a survey. Antiviral Res 2001;49:55-74.

54 Stebbing J, Bower M. Comparative pharmacogenomics of antiretroviral and cytotoxic treatments. Lancet Oncol 2006;7:61-8.

55 François T, lgual J, Cadranel J, et al. Bronchial cancer in patients infected with human immunodeficiency virus. Report of three patients. Rev Pneumol Clin 1990:46:99-102.

56 Courtot $\mathrm{H}$, Martin C, Charvier A, et al. Adenocarcinoma of unknown primary site with thoracic localization and HIV: four case reports. Rev Med Interne 1999;20:272-6.

57 Aviram G, Fishman JE, Schwartz DS. Metachronous primary carcinomas of the lung in an HIV-infected patient. AIDS Patient Care STDS 2001;15:297-300

58 Burke $M$, Furman $A$, Hoffman $M$, et al. Lung cancer in patients with HIV infection: is it AIDS-related? HIV Med 2004:5:110-4.
59 Flores MR, Sridhar KS, Thurer RJ, et al. Lung cancer in patients with human immunodeficiency virus infection. Am J Clin Oncol 1995; 18:59-66.

60 Ricaurte JC, Hoerman MF, Nord JA, et al. Lung cancer in HIV-infected patients: a one-year experience. Int J STD AIDS 2001;12:100-2.

61 Alshafie MT, Donaldson B, Oluwole SF. Human immunodeficiency virus and lung cancer. Br J Surg 1997;84:1068-71.

62 Spano JP, Massiani MA, Bentata M, et al. Lung cancer in patients with HIV Infection and review of the literature. Med Oncol 2004:21:109-15.

63 Demopoulos BP, Vamvakas E, Ehrlich JE, et al. Non-acquired immunodeficiency syndrome-defining malignancies in patients with human immunodeficiency virus. Arch Pathol Lab Med 2003;127:589-92.

64 Hader SL, Smith DK, Moore JS, et al. HIV infection in women in the United States: status at the Millennium. JAMA 2001;285:1186-92.

65 Bazot M, Cadranel J, Khalil A, et al. Computed tomographic diagnosis of bronchogenic carcinoma in HIV-infected patients. Lung Cancer 2000;28:203-9

66 Gruden JF, Webb WR, Yao DC, et al. Bronchogenic carcinoma in 13 patients infected with the human immunodeficiency virus (HIV): clinical and radiographic findings. J Thorac Imaging 1995;10:99-105.

67 White CS, Haramati LB, Elder KH, et al. Carcinoma of the lung in HIVpositive patients: findings on chest radiographs and $\mathrm{CT}$ scans. AJR Am J Roentgenol 1995; 164:593-7.

68 Jasmer RM, Edinburgh KJ, Thompson A, et al. Clinical and radiographic predictors of the etiology of pulmonary nodules in HIV-infected patients. Chest 2000;117:1023-30.

69 Fishman JE, Schwartz DS, Sais GJ, et al. Bronchogenic carcinoma in HIVpositive patients: findings on chest radiographs and CT-scan. AJR Am J Roentgenol 1995; 164:57-61.

70 Cadranel J, Chouaid C, Denis M, et al. Causes of pleural effusion in 75 HIVinfected patients. Chest 1993; 104:655

71 Cooley TP. Non-AIDS-defining cancer in HIV-infected people. Hematol Oncol Clin North Am 2003;17:889-99.

72 Alberg AJ, Samet JM. Epidemiology of lung cancer. Chest 2003;123:21S-49S

73 Charloux A, Quoix E, Wolkove N, et al. The increasing incidence of lung adenocarcinoma: reality or artefact? A review of the epidemiology of lung adenocarcinoma. Int J Epidemiol 1997:26:14-23.

74 Biggar RJ, Engels EA, Ly S, et al. Survival after cancer diagnosis in persons with AIDS. J Acquir Immune Defic Syndr 2005;39:293-9.

75 Tammemagi CM, Neslund-Dudas C, Simoff M, et al. Impact of comorbidity on lung cancer survival. Int J Cancer 2003;103:792-802.

76 Powles T, Nelson M, Bower M. HIV-related lung cancer: a growing concern? Int J STD AIDS 2003;14:647-51.

77 Thurer RJ, Jacobs JP, Holland FW 2nd, et al. Surgical treatment of lung cancer in patients with human immunodeficiency virus. Ann Thorac Surg 1995; 60:599-602.

78 Massera F, Rocco G, Rossi G, et al. Pulmonary resection for lung cancer in HIV-positive patients with low ( $<200$ lymphocytes $\left./ \mathrm{mm}^{3}\right) \mathrm{CD} 4(+)$ count. Lung Cancer 2000:29:147-9.

79 Kivisto KT, Kroemer HK, Eichelbaum M. The role of human cytochrome P450 enzymes in the metabolism of anticancer agents: implications for drug interactions. Br J Clin Pharmacol 1995;40:523-30.

80 Gulick R. Combination therapy for patients with HIV-1 infection: the use of dual nucleoside analogues with protease inhibitors and other agents. AIDS 1998;12:S17-22

81 Flexner C. HIV-protease inhibitors. N Engl J Med 1998;338:1281-92.

82 Rowinski EK, Donehower RC. Pharmacology of cancer chemotherapyantimicrotubule agents. In: Devita VT, Hellman S, Rosenberg SA, eds. Cancer principles and practice. 5th ed. Philadelphia: Lippincott-Raven Publishers, 1997:467-83.

83 Washington CB, Duran GE, Man MC, et al. Interaction of anti-HIV protease inhibitors with the multidrug transporter P-glycoprotein (P-gp) in human cultured cells. J Acquir Immune Defic Syndr Hum Retrovirol 1998; 19:203-9.

84 Hirsh MS, D'Aquila RT, Kaplan JC, eds. AIDS: biology, diagnosis, treatment and prevention, 4th ed. Philadelphia: Lippincott-Raven, 1997.

85 Kelly K, Crowley J, Bunn PA Jr, et al. Randomized phase III trial of paclitaxel plus carboplatin versus vinorelbine plus cisplatin in the treatment of patients with advanced non-small-cell lung cancer: a Southwest Oncology Group trial. J Clin Oncol 2001;19:3210-8.

86 Scagliotti GV, De Marinis F, Rinaldi M, et al. Italian Lung Cancer Project. Phase III randomized trial comparing three platinum-based doublets in advanced non-small-cell lung cancer. J Clin Oncol 2002;20:4285-91.

87 Richman DD, Fischl MA, Grieco MH, et al. The toxicity of azidothymidine (AZT) in the treatment of patients with AIDS and AIDS-related complex. A double-blind, placebo-controlled trial. N Engl J Med 1987;317:192-7.

88 Tan B, Ratner $L$. The use of new antiretroviral therapy in combination with chemotherapy. Curr Opin Oncol 1997;9:455-64.

89 Bower M, McCall-Peat N, Ryan N, et al. Protease inhibitors potentiate chemotherapy-induced neutropenia. Blood 2004;104:2943-6.

90 Powles T, Imami N, Nelson M, et al. Effects of combination chemotherapy and highly active antiretroviral therapy on immune parameters in HIV-1 associated lymphoma. AIDS 2002;16:531-6.

91 Hakim FT, Cepeda R, Kaimei S, et al. Constrains on CD4 recovery post chemotherapy in adults. Blood 1997;90:3789-98.

92 Martin JE, Besh L. Prophylaxis against opportunistic infections in persons infected with human immunodeficiency virus. Am J Med Sci 2004:328:64-9.

93 Costleigh BJ, Miyamoto CT, Micaily B, et al. Heightened sensitivity of the esophagus to radiation in a patient with AIDS. Am J Gastroenterol 1995;90:812-5. 
94 Leigh BR, Lau DH. Severe esophageal toxicity after thoracic radiation therapy for lung cancer associated with the human immunodeficiency virus: a case report and review of the literature. Am J Clin Oncol 1998;21:479-81.

95 Miller AB, Hoogstraten B, Staquet $M$, et al. Reporting results of cancer treatment. Cancer 1981;47:207-14.

96 Cooper JS, Fried PR, Laubenstein L. Initial observations of the effect of radiotherapy on epidemic Kaposi's sarcoma. JAMA 1984;252:934-5.

97 Chak LY, Gill PS, Levine AM, et al. Radiation therapy for acquired immunodeficiency syndrome-related Kaposi's sarcoma. J Clin Oncol 1988;6:863-7.

98 Volberding P. Treatment of malignant disease in AIDS patients. AIDS 1988;2(Suppl 1):S169-75.
99 Vallis KA. Glutathione deficiency and radiosensitivity in AIDS patients. Lancet 1991;337:918-9.

100 Buhl R, Jaffe HA, Holroyd KJ, et al. Systemic glutathione deficiency in symptom-free HIV-seropositive individuals. Lancet 1989;334:1294-8.

101 Boal DK, Newburger PE, Teele RL. Esophagitis induced by combined radiation and adriamycin. AJR Am J Roentgenol 1979;132:567-70.

102 Rodriguez R, Fontanesi J, Meyer JL, et al. Normal-tissue effects of irradiation for Kaposi's sarcoma/AIDS. Front Radiat Ther Oncol 1989;23:150-9.

103 Senan S, De Ruysscher D, Giraud P, et al. Literature-based recommendations for treatment planning and execution in high-dose radiotherapy for lung cancer. Radiother Oncol 2004;71:139-46.

\section{LUNG ALERT}

\section{Allergen sensitisation and impaired lung function in children}

$\Delta$ Illi S, von Mutius E, Lau S, et al. Perennial allergen sensitisation early in life and chronic asthma in children: a birth cohort study. Lancet 2006;368:763-70

$\mathrm{T}$ his study investigated the role of allergic sensitisation early in life as a factor which may contribute to the progressive loss of pulmonary function in children with persistent asthma. 1314 children were followed from birth to age 13. IgE measurements and parental interviews about their child's asthma were conducted regularly. Allergen exposure, lung function, bronchodilator response, and histamine challenge were also assessed.

Sensitisation and concomitant exposure to high levels of house dust mite, cat and dog hair allergens in the first 3 years of life was associated with loss of lung function at school age: $\mathrm{FEV}_{1} / \mathrm{FVC} 87.4 v 92.6$ for those not sensitised $(\mathrm{p}<0.0001)$, and $\mathrm{MEF}_{50} 86.4$ and 101.5 $(\mathrm{p}=0.0031)$ respectively. In sensitised children with wheeze, high exposure levels also enhanced the development of airway hyperresponsiveness. Sensitisation and exposure later in life had less effect and seasonal allergens had no role. $90 \%$ of children with wheeze but no atopy were asymptomatic at school age and retained normal lung function to age 13.

This study shows that continuing allergic airway inflammation beginning in the first 3 years of life contributes to airway hyperresponsiveness and impairment of lung function at school age. Further investigation is required to see if early inhaled corticosteroid treatment in atopic wheezy infants can prevent loss of lung function. In non-atopic wheezing children the need for corticosteroids on a regular basis should be reassessed as they have a good prognosis.

U Gupta

Senior House Officer, William Harvey Hospital, Kent, UK; urmi33@hotmail.com 